Published in final edited form as:

Curr Opin Pediatr. 2014 June ; 26(3): 328-333. doi:10.1097/MOP.0000000000000090.

\title{
Recent evidence on the management of bronchiolitis
}

\author{
Alan R. Schroeder, MD ${ }^{1}$ and Jonathan M. Mansbach, MD, MPH ${ }^{2}$ \\ ${ }^{1}$ Department of Pediatrics, Santa Clara Valley Medical Center, San Jose, CA \\ ${ }^{2}$ Department of Medicine, Boston Children's Hospital, Harvard Medical School, Boston, MA
}

\begin{abstract}
Purpose of Review-Bronchiolitis is a common condition in children $<2$ years and is a leading cause of infant hospitalization. While there is significant variability in testing and treatment of children with bronchiolitis, diagnostic testing rarely improves care, and no currently available pharmacologic options have been proven to provide meaningful benefit or improve outcomes.
\end{abstract}

Recent Findings-Beta-agonists continue to be used frequently despite evidence that they do not reduce hospital admissions or length-of-stay. In general, therapies initially considered promising were subsequently proven ineffective, a pattern seen in studies on corticosteroids, and more recently with nebulized racemic epinephrine and hypertonic saline. Recent research has improved our understanding of the viral epidemiology of bronchiolitis, with increasing recognition of viruses other than respiratory syncytial virus and better awareness of the role of viral coinfections. How these findings will translate into improved outcomes remains uncertain.

Summary-Much of the emphasis of the last few decades of bronchiolitis clinical care and research has centered on the identification and testing of novel therapies. Future quality improvement efforts should focus more on the limitation of unnecessary testing and treatments. Future research should include identification of subgroups of children with bronchiolitis that may benefit from focused clinical interventions.

\section{Keywords}

bronchiolitis; respiratory syncytial virus; rhinovirus; overutilization; hypertonic saline; pulse oximetry

\section{INTRODUCTION}

Viral bronchiolitis is a leading cause of hospitalization in infants and leads to at least one office visit in approximately $10 \%$ of children < 2 years.(1) Despite a lack of supporting evidence, many interventions continue to be used excessively, prompting efforts to curb unnecessary testing and treatments. $(2,3)$ While there have been some signs of success on reducing excessive care in bronchiolitis, (3-6) substantial overuse and practice variation

Contact information for corresponding author: Alan R. Schroeder, MD, Department of Pediatrics, Santa Clara Valley Medical Center, 751 S Bascom Ave, San Jose, CA 95128, Phone (408) 885-3612, Fax (408) 885-5263, Alan.Schroeder@hhs.sccgov.org.

There are no financial conflicts of interest. 
persist. In this review, we will highlight recent developments in bronchiolitis research, focusing on epidemiology, diagnostic testing, and therapeutics.

\section{EPIDEMIOLOGY}

During the 1980's and 1990's, hospitalizations for bronchiolitis increased 2.4-fold in the US, likely secondary to the advent of widespread pulse oximetry use and the general acceptance of hypoxemia as an admission criterion. $(7,8)$ During this same time period, however, bronchiolitis mortality rates did not change,(9) suggesting that many of these hospitalizations may have been unnecessary. There are some encouraging signs that the rate of unnecessary hospitalizations is beginning to decrease. From 2000 to 2009, hospitalizations in children 0-11 months began to decrease slightly, though the mean charges per hospitalization increased 34\%, likely because of an increase in children with high-risk medical conditions and increased severity of disease as demonstrated by increased use of mechanical ventilation. (10)

\section{Virology}

Recent investigations have better elucidated the viral epidemiology of bronchiolitis and the significance of viral co-infections. In a prospective, multicenter study on bronchiolitis (the Multicenter Airway Research Collaboration 30 [MARC-30] study), involving 2207 children $<2$ years, we demonstrated that $30 \%$ of children hospitalized with bronchiolitis were infected with $>1$ virus. (11) Although most (72\%) children in this study were infected with respiratory syncytial virus (RSV), a substantial proportion (26\%) was infected with human rhinovirus (HRV). Children with HRV alone were more likely to have a shorter LOS, a finding seen previously in a Finnish sample.(12) The MARC study also demonstrated that viral etiology did not predict apnea, challenging a long-held belief that RSV increases the apnea risk more than other viruses in bronchiolitis.(13) Finally, the study demonstrated that while the viral etiology had some impact on LOS, it did not predict the need for positive pressure ventilation (PPV), consistent with another recent investigation suggesting that clinical factors were more predictive of bronchiolitis severity than the viral etiology.(14)

\section{DIAGNOSTIC TESTING}

Infants with bronchiolitis often undergo extensive and largely needless, diagnostic evaluation. The 2006 American Academy of Pediatrics (AAP) bronchiolitis clinical practice guideline (CPG) recommended no routine laboratory or radiologic studies in bronchiolitis, (15) but there is evidence that a substantial amount of testing is still performed.

\section{Chest radiographs}

Two recent investigations have analyzed trends in emergency department chest x-ray (CXR) use. Knapp et al(16) demonstrated that CXR use did not change between 1995 and 2009 while an analysis by Johnson et al(17) revealed a statistically significant decline from $65 \%$ before the 2006 AAP guidelines to $49 \%$ after the guidelines. While this decline is encouraging, CXRs are still being performed on almost half of children with bronchiolitis. CXRs are associated with avoidable costs, radiation exposure, and subsequent antibiotic administration.(18) Because CXRs are generally obtained on presentation, efforts to reduce 
imaging should focus on emergency medicine and outpatient clinicians. Quality improvement efforts involving pediatric hospitalists do not appear to reduce unnecessary therapies that occur at presentation.(3)

\section{Viral testing}

While the role of virology testing in current clinical care is limited, and is discouraged in the 2006 AAP guidelines(15), viral testing is strongly encouraged in clinical trials and epidemiologic studies of bronchiolitis in order to identify potentially important differences in outcomes based on viral etiology, Although infection control measures such as isolation and cohorting are sometimes cited as justifications for viral testing, the $30 \%$ co-infection rate(11) may limit the effectiveness of these measures. Moreover, false negatives are possible, especially when rapid antigen testing is used, $(19,20)$ if the specimen is obtained by a nasal swab rather than a nasal aspirate,(21) or if unsatisfactory specimens are obtained.

As part of a quality improvement effort at Santa Clara Valley Medical Center during one year of the MARC-30 study, the clinical care viral testing results (performed either at the referring emergency rooms/clinics or on the inpatient unit, using variable viral panels and techniques) were compared with the samples collected for study purposes, which were obtained via nasopharyngeal aspiration and tested for 16 viruses by polymerase chain reaction testing at Baylor College of Medicine.(11) Although small numbers and unpublished data, 23 of 25 (92\%) patients who tested negative locally had positive testing for at least one virus in the MARC-30 laboratory at the Baylor. Furthermore, of the 16 patients who tested positive locally for a single virus, $9(56 \%)$ had a second virus detected at Baylor. While expansion and/or refinement of viral testing capabilities may reduce these types of false negative results, there are associated costs of expanded testing, and no clear evidence that viral testing improves acute care.

\section{Fever evaluation}

Some infants with bronchiolitis have fever. As a result, laboratory tests are often ordered to help evaluate for possible serious bacterial infections. The probability of bacteremia or bacterial meningitis in young infants with bronchiolitis is extremely low, (22-24) making blood and cerebrospinal fluid testing low-yield. The probability of urinary tract infection (UTI), on the other hand, is reportedly high enough (3-7\%) to warrant consideration of urine testing. However, most of these studies have not required a positive urinalysis to confirm the diagnosis of UTI, as currently recommended by the AAP for infants 2 months -2 years.(25) A portion of these UTIs may therefore simply represent colonization or asymptomatic bacteruria, found in over $1 \%$ of healthy infants, and thereby lead to an overstated risk for UTI in this patient population. $(26,27)$

\section{THERAPEUTICS}

In one of the first reviews on bronchiolitis, Drs. Wright and Beem cautioned that "the principle of primum non nocere should temper frustrated anxiety to do something-anythingto relieve severe dyspnea", and that an infant's "energies should not be frittered away by the 
annoyance of unnecessary or futile medications and procedures."(28) Unfortunately, these admonitions from nearly 50 years ago appear to have gone largely unheeded.

\section{Bronchodilators}

The 2006 AAP bronchiolitis CPG discourages routine use of bronchodilators. However, this recommendation is qualified by the suggestion that a "carefully monitored trial...is an option."(15) Perhaps because this therapeutic door is left open, the administration of betaagonists in bronchiolitis is still widespread. Even after the initiation of a quality improvement effort in 17 pediatric hospitals that was successful in reducing unnecessary therapies in bronchiolitis, infants continued to receive a mean of 4.3 doses of albuterol over the course of their hospitalization.(3) Over half of patients with bronchiolitis seen in emergency departments across the country continue to receive bronchodilators.(17) The most recent meta-analysis on the use of beta-agonists, which includes 28 trials involving 1912 patients, demonstrates that outpatient use does not reduce the rate of hospitalization and that inpatient use does not shorten length-of-stay.(29)

A concern about "trials" of albuterol is that they may not be "carefully monitored" as advocated by the AAP, and they are often accompanied by other interventions, such as antipyretics or intravenous fluids which, when coupled with the benefits of time, may lead to clinical improvement that is interpreted as a "response to albuterol." For this reason, labeling a child with bronchiolitis as an "albuterol responder" can be questionable depending on the other interventions occurring simultaneously.

Because the pathophysiology of bronchiolitis is characterized by bronchial wall edema and epithelial sloughing but not bronchospasm,(30) the vasoconstrictive attributes of alphaagonists should theoretically make them more effective than beta-agonists. Indeed, a metaanalysis of 19 trials involving 2256 patients demonstrated a small but significant reduction in hospitalization rates with epinephrine compared to placebo (relative risk $0.67,95 \%$ confidence interval [CI] 0.50 - 0.89) and a shorter LOS with epinephrine compared to betaagonists (mean -0.28 days, $95 \% \mathrm{CI}-0.46$ to -0.09 days), but not when compared to saline. (31) However, in a more recent trial involving 404 hospitalized infants, inhaled racemic adrenaline was no better than inhaled saline.(32) Interestingly, infants in this trial had a shorter LOS when either treatment (adrenaline or saline) was given "on-demand" rather than more frequently on a fixed schedule, supporting the notion that interventions of any kind can be harmful to a struggling infant with bronchiolitis.(28) A recent case report of an otherwise healthy infant who developed unstable ventricular tachycardia after a single dose of nebulized epinephrine(33) highlights the notion that no intervention is benign.

\section{Hypertonic saline}

The putative effect of hypertonic saline (HTS) in bronchiolitis is to absorb mucosal water in the bronchioles and enhance mucociliary clearance.(34) Although the most recent metaanalysis seems promising in terms of LOS reduction (mean -1.15 days, $95 \% \mathrm{CI}-1.49$ to $-0.82),(35)$ the benefit appears to be concentrated in studies where the mean LOS in both treatment arms was surprisingly long (5-7 days), i.e. less generalizable to US populations where the mean LOS is closer to 2-3 days. Furthermore, trials published since this meta- 
analysis have demonstrated no benefit of $\operatorname{HTS},(36,37)$ a pattern that is all too familiar in bronchiolitis research.(38)

\section{Corticosteroids}

Like HTS, early trials of steroids in bronchiolitis were encouraging.(39) However, the evidence continues to mount that steroids are ineffective, (40) generating acceptance that corticosteroids are unnecessary and overused in bronchiolitis. $(2,15,41)$ One large trial demonstrated no benefit of dexamethasone over placebo but did suggest that the combination of dexamethasone and racemic epinephrine reduced hospitalization rates at day 7.(42) Why this combination of therapies would be effective at day 7 but not in the short term remains unclear. Furthermore, this finding, which has yet to be replicated in other studies, did not retain statistical significance $(\mathrm{P}=.07)$ after after adjustment for multiple comparisons.(43)

There are some lingering questions about whether corticosteroids might be effective in patients who have rhinovirus infection,(12) or more generally in those at risk for asthma (i.e. eczema or a first-degree relative with asthma), a population in whom a recent trial involving 200 patients found benefit of dexamethasone in terms of LOS reduction.(44) However, these findings are in contrast to those from a large study on corticosteroids in bronchiolitis,(45) in which $\sim 2 / 3$ of the 600 patients studied were reported to have either eczema or a family history of asthma, and corticosteroids demonstrated no benefit in this subgroup. Similarly, in a slightly older population (10 months -6 years) of children with virus-induced wheezing, systemic corticosteroids conferred no decrease in hospital LOS to the 124 children who were classified as being at high risk for asthma. $(46,47)$ A more recent analysis of a small number of children with rhinovirus bronchiolitis demonstrated that there may be longer term benefits of corticosteroids to reduce future wheezing,(48) but the interpretation is based on a relatively small sample size and warrants repetition.

\section{RSV Immunoprophylaxis}

Palivizumab is a monoclonal antibody used to limit the morbidity from RSV infections in high risk infants (prematurity, chronic lung disease, and congenital heart disease). Although palivizumab has not improved RSV mortality rates, trials have demonstrated a modest reduction in hospitalization rates. $(49,50)$ However, in the lower risk groups (for whom prophylaxis continues to be given), the number-needed-to-treat (NNT) is in the range of 19-170, conferring an unfavorable cost:benefit ratio given the high cost of the drug.(51) Whether palivizumab prevents future wheezing episodes, as suggested by relatively preliminary data from two industry sponsored trial, $(52,53)$ remains unproven. Clearly, the causal relationship between RSV or other viruses and the future development of asthma requires ongoing investigation.

\section{SUPPORTIVE THERAPIES}

The lack of benefit of pharmacologic agents leaves many practitioners wondering what, if anything, they can do for infants with bronchiolitis. General supportive measures include 
suctioning, hydration, and supplemental oxygen.(15) Infants with respiratory failure are generally managed in intensive care units with positive pressure ventilation.(54)

\section{Suctioning}

Suctioning is a mainstay of both inpatient and outpatient bronchiolitis management, but this intervention has been poorly studied. While removal of mucus from a clogged nostril is intuitively an intervention that should not require a randomized trial to prove benefit, there are lingering uncertainties over technique and frequency. One recent study showed that LOS was prolonged in infants who received deep suctioning or who had long lapses ( $>4$ hour) between suctioning,(55) suggesting that superficial suctioning may be the safest and most effective method.

\section{Supplemental oxygen}

The use of supplemental oxygen is another mainstay of inpatient management, though considerable controversy exists over when to initiate and discontinue oxygen therapy. Hypoxemia tends to drive hospitalization(7) and discharge $(56,57)$ decisions, and oxygen saturation thresholds tend to vary substantially. The 2006 AAP bronchiolitis CPG recommends providing oxygen for saturations "persistently below 90\%".(15) Some have voiced concern that cognitive impairment can occur even in children exposed to saturations in the $90-94 \%$ range, (58) a provocative critique given a recent finding that a saturation threshold of $94 \%$ could prolong LOS in bronchiolitis by an estimated 22 hours compared to a threshold of $90 \%$.(59) However, the research cited by the authors applies to children with sleep-disordered breathing and congenital heart disease,(60) populations that are clearly quite different from infants with acute bronchiolitis. Even healthy young infants have been documented to have intermittent desaturations to $<90 \%$. $(61,62)$ Therefore, continuous pulse oximetry may detect hypoxemia of unclear significance in young infants with bronchiolitis, thereby prolonging the hospitalization. $(56,57)$ Avoiding continuous pulse oximetry in infants who are not on oxygen may help reduce excessive hospital days. $(2,15)$

Another potential LOS reduction strategy is to send children with bronchiolitis home on oxygen, which may be both safe and effective. (63-65) However, studies on this strategy were all conducted in high-altitude areas, where hypoxemia is more frequent if the same oxygen saturation thresholds are used. Survey data suggest that this practice has not yet caught on in the rest of the US.(66)

In infants who are struggling to breathe, high-flow nasal cannula (HFNC) oxygen therapy is being used with increasing frequency. HFNC is appealing to many physicians as it appears to be less agitating to children than nasal continuous or bilevel positive airway pressure, and it may prevent endotracheal intubation in some cases of bronchiolitis.(67-69) Randomized trials of HFNC are greatly needed to assess efficacy and determine the optimal timing of initiation, and the safety profile needs further clarification.(70)

\section{CONCLUSION}

The last few decades of bronchiolitis research have seen an abundance of studies evaluating various therapeutic strategies. Many therapies initially seem to hold some promise until 
proven ineffective by subsequent and generally larger trials, a phenomenon that may be attributed to publication bias.(71) Some questions remain over the possibility that specific subgroups of patients might benefit from a particular therapeutic interventions (e.g. children with prior wheezing, atopy, or infections with certain viruses like rhinovirus $(12,48,72)$ ). In an ongoing multicenter study (www.windstudy.org) supported by the NIH, the MARC-35 investigators (www.emnet-usa.org) are examining multiple risk factors for the development of recurrent wheezing and eventual asthma in children hospitalized with bronchiolitis. It is possible that results from future trials of medications and interventions may vary based on newly identified subgroups of children. However, with an increasing emphasis on waste and escalating costs in our healthcare system,(73) current efforts should focus on strategies aimed at decreasing tests and therapies that have demonstrated no benefit to date for children with bronchiolitis. As suggested in 1965,(28) clinicians should focus on not giving in to the "frustrated anxiety to do something-anything-to relieve severe dyspnea", and limit their interventions whenever possible.

\section{ACKNOWLEDGMENTS}

Dr. Mansbach was supported by the grants U01 AI-67693 and K23 AI-77801 from the National Institutes of Health (Bethesda, MD). Dr. Schroeder's institution received funding from U01 AI-67693 for site participation and enrollment of patients. The content of this manuscript is solely the responsibility of the authors and does not necessarily represent the official views of the National Institute of Allergy and Infectious Diseases or the National Institutes of Health.

\section{REFERENCES}

1. Mansbach JM, Pelletier AJ, Camargo CA Jr. US outpatient office visits for bronchiolitis, 1993-2004. Ambul Pediatr. Jul-Aug;2007 7(4):304-7. [PubMed: 17660102]

2*. Quinonez RA, Garber MD, Schroeder AR, Alverson BK, Nickel W, Goldstein J, et al. Choosing wisely in pediatric hospital medicine: five opportunities for improved healthcare value. J Hosp Med. Sep; 2013 8(9):479-85. [PubMed: 23955837] [The first “Top 5" list put out by a pediatric subspecialty group for the Choosing Wisely Campaign. Four of the five recommendations involve limiting unnecessary care in bronchiolitis.]

3*. Ralston S, Garber M, Narang S, Shen M, Pate B, Pope J, et al. Decreasing unnecessary utilization in acute bronchiolitis care: results from the value in inpatient pediatrics network. J Hosp Med. Jan; 2013 8(1):25-30. [PubMed: 23047831] [A successful collaborative quality improvement effort in 17 centers to standardize care in bronchiolitis. Albuterol usage decreased significantly.]

4. Akenroye AT, Baskin MN, Samnaliev M, Stack AM. Impact of a Bronchiolitis Guideline on ED Resource Use and Cost: A Segmented Time-Series Analysis. Pediatrics. Dec 9.2013

5. McCulloh RJ, Smitherman SE, Koehn KL, Alverson BK. Assessing the impact of national guidelines on the management of children hospitalized for acute bronchiolitis. Pediatr Pulmonol. Jul 19.2013

6. Parikh K, Hall M, Teach SJ. Bronchiolitis Management Before and After the AAP Guidelines. Pediatrics. Dec 2.2013

7. Mallory MD, Shay DK, Garrett J, Bordley WC. Bronchiolitis management preferences and the influence of pulse oximetry and respiratory rate on the decision to admit. Pediatrics. Jan; 2003 111(1):e45-51. [PubMed: 12509594]

8. Shay DK, Holman RC, Newman RD, Liu LL, Stout JW, Anderson LJ. Bronchiolitis-associated hospitalizations among US children, 1980-1996. JAMA. Oct 20; 1999 282(15):1440-6. [PubMed: 10535434]

9. Shay DK, Holman RC, Roosevelt GE, Clarke MJ, Anderson LJ. Bronchiolitis-associated mortality and estimates of respiratory syncytial virus-associated deaths among US children, 1979-1997. J Infect Dis. Jan 1; 2001 183(1):16-22. [PubMed: 11076709] 
10. Hasegawa K, Tsugawa Y, Brown DF, Mansbach JM, Camargo CA Jr. Trends in bronchiolitis hospitalizations in the United States, 2000-2009. Pediatrics. Jul; 2013 132(1):28-36. [PubMed: 23733801]

11**. Mansbach JM, Piedra PA, Teach SJ, Sullivan AF, Forgey T, Clark S, et al. Prospective multicenter study of viral etiology and hospital length of stay in children with severe bronchiolitis. Arch Pediatr Adolesc Med. Aug; 2012 166(8):700-6. [PubMed: 22473882] [The first publication from the MARC-30 bronchiolitis study, which demonstrated that a wide variety of viruses cause bronchiolitis, and that $30 \%$ of children are infected with at least 2 viruses.]

12. Jartti T, Lehtinen P, Vanto T, Hartiala J, Vuorinen T, Makela MJ, et al. Evaluation of the efficacy of prednisolone in early wheezing induced by rhinovirus or respiratory syncytial virus. Pediatr Infect Dis J. Jun; 2006 25(6):482-8. [PubMed: 16732144]

13*. Schroeder AR, Mansbach JM, Stevenson M, Macias CG, Fisher ES, Barcega B, et al. Apnea in children hospitalized with bronchiolitis. Pediatrics. Nov; 2013 132(5):e1194-201. [PubMed: 24101759] [This article challenges the long-held notion that RSV increases the risk of apnea more than other viruses by demonstrating that the apnea risk is similar across all viral etiologies in bronchiolits.]

14. Ricart S, Marcos MA, Sarda M, Anton A, Munoz-Almagro C, Pumarola T, et al. Clinical risk factors are more relevant than respiratory viruses in predicting bronchiolitis severity. Pediatr Pulmonol. May; 2013 48(5):456-63. [PubMed: 22949404]

15. Diagnosis and management of bronchiolitis. Pediatrics. Oct; 2006 118(4):1774-93. [PubMed: 17015575]

16. Knapp JF, Simon SD, Sharma V. Variation and trends in ED use of radiographs for asthma, bronchiolitis, and croup in children. Pediatrics. Aug; 2013 132(2):245-52. [PubMed: 23878045]

17. Johnson LW, Robles J, Hudgins A, Osburn S, Martin D, Thompson A. Management of bronchiolitis in the emergency department: impact of evidence-based guidelines? Pediatrics. Mar; 2013 131(Suppl 1):S103-9. [PubMed: 23457145]

18. Schuh S, Lalani A, Allen U, Manson D, Babyn P, Stephens D, et al. Evaluation of the utility of radiography in acute bronchiolitis. J Pediatr. Apr; 2007 150(4):429-33. [PubMed: 17382126]

19. Aslanzadeh J, Zheng X, Li H, Tetreault J, Ratkiewicz I, Meng S, et al. Prospective evaluation of rapid antigen tests for diagnosis of respiratory syncytial virus and human metapneumovirus infections. J Clin Microbiol. May; 2008 46(5):1682-5. [PubMed: 18337386]

20. Henrickson KJ, Hall CB. Diagnostic assays for respiratory syncytial virus disease. Pediatr Infect Dis J. Nov; 2007 26(11 Suppl):S36-40. [PubMed: 18090198]

21. Meerhoff TJ, Houben ML, Coenjaerts FE, Kimpen JL, Hofland RW, Schellevis F, et al. Detection of multiple respiratory pathogens during primary respiratory infection: nasal swab versus nasopharyngeal aspirate using real-time polymerase chain reaction. Eur J Clin Microbiol Infect Dis. Apr; 2010 29(4):365-71. [PubMed: 20111881]

22. Levine DA, Platt SL, Dayan PS, Macias CG, Zorc JJ, Krief W, et al. Risk of serious bacterial infection in young febrile infants with respiratory syncytial virus infections. Pediatrics. Jun; 2004 113(6):1728-34. [PubMed: 15173498]

23. Ralston S, Hill V, Waters A. Occult serious bacterial infection in infants younger than 60 to 90 days with bronchiolitis: a systematic review. Arch Pediatr Adolesc Med. Oct; 2011 165(10):9516. [PubMed: 21969396]

24. Titus MO, Wright SW. Prevalence of serious bacterial infections in febrile infants with respiratory syncytial virus infection. Pediatrics. Aug; 2003 112(2):282-4. [PubMed: 12897274]

25. Roberts KB. Urinary tract infection: clinical practice guideline for the diagnosis and management of the initial UTI in febrile infants and children 2 to 24 months. Pediatrics. Sep; 2011 128(3):595610. [PubMed: 21873693]

26. Wettergren B, Hellstrom M, Stokland E, Jodal U. Six year follow up of infants with bacteriuria on screening. BMJ. Oct 13; 1990 301(6756):845-8. [PubMed: 2282422]

27. Wettergren B, Jodal U. Spontaneous clearance of asymptomatic bacteriuria in infants. Acta Paediatr Scand. Mar; 1990 79(3):300-4. [PubMed: 2333743]

28. Wright FH, Beem MO. Diagnosis and Treatment: Management of Acute Viral Bronchiolitis in Infancy. Pediatrics. Feb.1965 35:334-7. [PubMed: 14261972] 
29. Gadomski AM, Brower M. Bronchodilators for bronchiolitis. Cochrane Database Syst Rev. 2010; (12):CD001266. [PubMed: 21154348]

30. Zorc JJ, Hall CB. Bronchiolitis: recent evidence on diagnosis and management. Pediatrics. Feb; 2010 125(2):342-9. [PubMed: 20100768]

31. Hartling L, Bialy LM, Vandermeer B, Tjosvold L, Johnson DW, Plint AC, et al. Epinephrine for bronchiolitis. Cochrane Database Syst Rev. 2011; (6):CD003123. [PubMed: 21678340]

32**. Skjerven HO, Hunderi JO, Brugmann-Pieper SK, Brun AC, Engen H, Eskedal L, et al. Racemic adrenaline and inhalation strategies in acute bronchiolitis. N Engl J Med. Jun 13; 2013 368(24): 2286-93. [PubMed: 23758233] [Large randomized trial showing no benefit of nebulized epinephrine over placebo. However, infants who got less frequent interventions (epinephrine or placebo) had a shorter length-of-stay, supporting the notion that less may be more in bronchiolitis therapy.]

33. Toaimah FH, Al-Ansari K. Life-threatening cardiac arrhythmia after a single dose of nebulized epinephrine in pediatric emergency department. J Trop Pediatr. Dec; 2011 57(6):497-9. [PubMed: 21257674]

34. Mandelberg A, Amirav I. Hypertonic saline or high volume normal saline for viral bronchiolitis: mechanisms and rationale. Pediatr Pulmonol. Jan; 2010 45(1):36-40. [PubMed: 20014350]

35*. Zhang L, Mendoza-Sassi RA, Wainwright C, Klassen TP. Nebulised hypertonic saline solution for acute bronchiolitis in infants. Cochrane Database Syst Rev. 2013; 7:CD006458. [PubMed: 23900970] [Latest meta-analysis on hypertonic saline, demonstrating a reduction in length-ofstay. However, two subsequent trials (Jacobs et al and Sharma et al) found no benefit..]

36. Jacobs JD, Foster M, Wan J, Pershad J. 7\% Hypertonic Saline in Acute Bronchiolitis: A Randomized Controlled Trial. Pediatrics. Dec 16.2013

37. Sharma BS, Gupta MK, Rafik SP. Hypertonic (3\%) saline vs $0.93 \%$ saline nebulization for acute viral bronchiolitis: a randomized controlled trial. Indian Pediatr. Aug; 2013 50(8):743-7. [PubMed: 23502662]

38. Cornfield DN. Bronchiolitis: Doing Less and Still Getting Better. Pediatrics. Dec 16.2013

39. Garrison MM, Christakis DA, Harvey E, Cummings P, Davis RL. Systemic corticosteroids in infant bronchiolitis: A meta-analysis. Pediatrics. Apr.2000 105(4):E44. [PubMed: 10742365]

40*. Fernandes RM, Bialy LM, Vandermeer B, Tjosvold L, Plint AC, Patel H, et al. Glucocorticoids for acute viral bronchiolitis in infants and young children. Cochrane Database Syst Rev. 2013; 6:CD004878. [PubMed: 23733383] [This meta-analysis on glucocorticoids in bronchiolitis found no benefit of inhaled or systemic corticosteroids on admissions or length-of-stay.]

41. Van Cleve WC, Christakis DA. Unnecessary care for bronchiolitis decreases with increasing inpatient prevalence of bronchiolitis. Pediatrics. Nov; 2011 128(5):e1106-12. [PubMed: 21987704]

42. Plint AC, Johnson DW, Patel H, Wiebe N, Correll R, Brant R, et al. Epinephrine and dexamethasone in children with bronchiolitis. N Engl J Med. May 14; 2009 360(20):2079-89. [PubMed: 19439742]

43. Alverson BK, Ralston S, Garber M. A cost analysis is premature. Pediatrics. Feb; 2011 127(2):e513-4. author reply e5-6. [PubMed: 21285330]

44. Alansari K, Sakran M, Davidson BL, Ibrahim K, Alrefai M, Zakaria I. Oral dexamethasone for bronchiolitis: a randomized trial. Pediatrics. Oct; 2013 132(4):e810-6. [PubMed: 24043283]

45. Corneli HM, Zorc JJ, Mahajan P, Shaw KN, Holubkov R, Reeves SD, et al. A multicenter, randomized, controlled trial of dexamethasone for bronchiolitis. N Engl J Med. Jul 26; 2007 357(4):331-9. [PubMed: 17652648]

46. Panickar J, Lakhanpaul M, Lambert PC, Kenia P, Stephenson T, Smyth A, et al. Oral prednisolone for preschool children with acute virus-induced wheezing. N Engl J Med. Jan 22; 2009 360(4): 329-38. [PubMed: 19164186]

47. Castro-Rodriguez JA, Holberg CJ, Wright AL, Martinez FD. A clinical index to define risk of asthma in young children with recurrent wheezing. Am J Respir Crit Care Med. Oct; 2000 162(4 Pt 1):1403-6. [PubMed: 11029352]

48*. Lukkarinen M, Lukkarinen H, Lehtinen P, Vuorinen T, Ruuskanen O, Jartti T. Prednisolone reduces recurrent wheezing after first rhinovirus wheeze: a 7-year follow-up. Pediatr Allergy 
Immunol. May; 2013 24(3):237-43. [PubMed: 23373881] [This article suggests there may be some long-term benefits of corticosteroids in the subpopulation of children with rhinovirus and wheezing.]

49. Palivizumab, a humanized respiratory syncytial virus monoclonal antibody, reduces hospitalization from respiratory syncytial virus infection in high-risk infants. The IMpact-RSV Study Group. Pediatrics. Sep; 1998 102(3 Pt 1):531-7.

50. Feltes TF, Cabalka AK, Meissner HC, Piazza FM, Carlin DA, Top FH Jr. et al. Palivizumab prophylaxis reduces hospitalization due to respiratory syncytial virus in young children with hemodynamically significant congenital heart disease. J Pediatr. Oct; 2003 143(4):532-40. [PubMed: 14571236]

51. Meissner HC, Kimberlin DW. RSV immunoprophylaxis: does the benefit justify the cost? Pediatrics. Nov; 2013 132(5):915-8. [PubMed: 24127478]

52. Blanken MO, Rovers MM, Molenaar JM, Winkler-Seinstra PL, Meijer A, Kimpen JL, et al. Respiratory syncytial virus and recurrent wheeze in healthy preterm infants. N Engl J Med. May 9; 2013 368(19):1791-9. [PubMed: 23656644]

53. Yoshihara S, Kusuda S, Mochizuki H, Okada K, Nishima S, Simoes EA. Effect of palivizumab prophylaxis on subsequent recurrent wheezing in preterm infants. Pediatrics. Nov; 2013 132(5): 811-8. [PubMed: 24127479]

54. Mansbach JM, Piedra PA, Stevenson MD, Sullivan AF, Forgey TF, Clark S, et al. Prospective multicenter study of children with bronchiolitis requiring mechanical ventilation. Pediatrics. Sep; 2012 130(3):e492-500. [PubMed: 22869823]

55. Mussman GM, Parker MW, Statile A, Sucharew H, Brady PW. Suctioning and length of stay in infants hospitalized with bronchiolitis. JAMA Pediatr. May; 2013 167(5):414-21. [PubMed: 23460088]

56. Schroeder AR, Marmor AK, Pantell RH, Newman TB. Impact of pulse oximetry and oxygen therapy on length of stay in bronchiolitis hospitalizations. Arch Pediatr Adolesc Med. Jun; 2004 158(6):527-30. [PubMed: 15184214]

57. Unger S, Cunningham S. Effect of oxygen supplementation on length of stay for infants hospitalized with acute viral bronchiolitis. Pediatrics. Mar; 2008 121(3):470-5. [PubMed: 18310194]

58. Bass JL, Gozal D. Oxygen therapy for bronchiolitis. Pediatrics. Mar.2007 119(3):611. [PubMed: 17332214]

59. Cunningham S, McMurray A. Observational study of two oxygen saturation targets for discharge in bronchiolitis. Arch Dis Child. Apr; 2012 97(4):361-3. [PubMed: 21388970]

60. Bass JL, Corwin M, Gozal D, Moore C, Nishida H, Parker S, et al. The effect of chronic or intermittent hypoxia on cognition in childhood: a review of the evidence. Pediatrics. Sep; 2004 114(3):805-16. [PubMed: 15342857]

61. Hunt CE, Corwin MJ, Lister G, Weese-Mayer DE, Neuman MR, Tinsley L, et al. Longitudinal assessment of hemoglobin oxygen saturation in healthy infants during the first 6 months of age. Collaborative Home Infant Monitoring Evaluation (CHIME) Study Group. J Pediatr. Nov; 1999 135(5):580-6. [PubMed: 10547246]

62. Hunt CE, Corwin MJ, Weese-Mayer DE, Ward SL, Ramanathan R, Lister G, et al. Longitudinal assessment of hemoglobin oxygen saturation in preterm and term infants in the first six months of life. J Pediatr. Sep; 2011 159(3):377-83. e1. [PubMed: 21481418]

63. Bajaj L, Turner CG, Bothner J. A randomized trial of home oxygen therapy from the emergency department for acute bronchiolitis. Pediatrics. Mar; 2006 117(3):633-40. [PubMed: 16510641]

64. Halstead S, Roosevelt G, Deakyne S, Bajaj L. Discharged on supplemental oxygen from an emergency department in patients with bronchiolitis. Pediatrics. Mar; 2012 129(3):e605-10. [PubMed: 22331343]

65. Sandweiss DR, Mundorff MB, Hill T, Wolfe D, Greene T, Andrews S, et al. Decreasing hospital length of stay for bronchiolitis by using an observation unit and home oxygen therapy. JAMA Pediatr. May; 2013 167(5):422-8. [PubMed: 23479000] 
66. Sandweiss DR, Kadish HA, Campbell KA. Outpatient management of patients with bronchiolitis discharged home on oxygen: a survey of general pediatricians. Clin Pediatr (Phila). May; 2012 51(5):442-6. [PubMed: 22157426]

67. McKiernan C, Chua LC, Visintainer PF, Allen H. High flow nasal cannulae therapy in infants with bronchiolitis. J Pediatr. Apr; 2010 156(4):634-8. [PubMed: 20036376]

68. Schibler A, Pham TM, Dunster KR, Foster K, Barlow A, Gibbons K, et al. Reduced intubation rates for infants after introduction of high-flow nasal prong oxygen delivery. Intensive Care Med. May; 2011 37(5):847-52. [PubMed: 21369809]

69. Wing R, James C, Maranda LS, Armsby CC. Use of high-flow nasal cannula support in the emergency department reduces the need for intubation in pediatric acute respiratory insufficiency. Pediatr Emerg Care. Nov; 2012 28(11):1117-23. [PubMed: 23114231]

70. Hegde S, Prodhan P. Serious air leak syndrome complicating high-flow nasal cannula therapy: a report of 3 cases. Pediatrics. Mar; 2013 131(3):e939-44. [PubMed: 23382446]

71. Ioannidis JP. Contradicted and initially stronger effects in highly cited clinical research. JAMA. Jul 13; 2005 294(2):218-28. [PubMed: 16014596]

72. Lehtinen P, Ruohola A, Vanto T, Vuorinen T, Ruuskanen O, Jartti T. Prednisolone reduces recurrent wheezing after a first wheezing episode associated with rhinovirus infection or eczema. J Allergy Clin Immunol. Mar; 2007 119(3):570-5. [PubMed: 17196244]

73. Berwick DM, Hackbarth AD. Eliminating waste in US health care. JAMA. Apr 11; 2012 307(14): 1513-6. [PubMed: 22419800] 


\section{KEY POINTS}

- Although bronchiolitis is a frequent cause of hospitalization and outpatient visits in infants and young children, few interventions are effective other than basic supportive care.

- Many pharmacologic therapies demonstrate initial promise but are proven ineffective in subsequent trials.

- There is increasing recognition of the role of rhinovirus and the frequency and relevance of viral co-infections. While testing for viruses in clinical practice currently has no clear benefit, additional research may clarify if infants with certain viruses respond more favorably to treatment. 